\title{
Rapid Study on the Impact of COVID-19 on the Personal and Official Wellbeing of PAC Staffs
}

\author{
Vivetha Gunaretnam (MSW(c), BSW Hons, Dip in Counselling) \\ National Institute of Social Development, Sri Lanka
}

\begin{abstract}
This paper addresses the impact of COVID- 19 on the personal and official wellbeing of PAC staff. The term COVID19 can be defined as Coronavirus disease for 2019. According to World Health Organization (WHO) Coronavirus disease (COVID-19) is an infectious disease caused by the SARS-CoV-2 Virus. The term personal wellbeing is a good, satisfactory, and desirable state of personal existence or life. It represents the personal aspect of the quality of the life (Janek Musek, 2014). According to International Labor Organization (ILO, 2015), workplace wellbeing is related to all aspects of working life, from the quality and safety of the physical environment to how workers feel about work, their working environment, the climate of the work, and work organization. The term Mental Health can be defined as a state of well-being in which an individual realizes his/her ability can cope with the normal stresses of life, can work productively, and can contribute to his or her community (WHO, 2015). This paper examines the impact of COVID-19 on the personal and official wellbeing of the Psychological Advisory Center (PAC) Staff. PAC is a well-known established organization that aims to promote the psychological wellbeing of the people globally and locally. Staff' are working in the organization and the researcher aimed to find out the COVID-19 impact on their personal and official wellbeing. In exploring the dependent variable of the impact of the COVID-19, the present paper discusses the independent variable such as personal and official wellbeing by accessing the knowledge; heard/seen stories, awareness of the symptoms, preventative measures, the government interventions. The criteria of Personal life impact, explore the impact as a person, impact as a family member, affecting needs and services, security, friendship, intimacy, and sense of connection. In exploring the official life with PAC, working conditions, decision-making skills, interaction with other colleagues, and working hours have been examined during the COVID-19 period.
\end{abstract}

\section{INTRODUCTION}

$\mathrm{T}$ he World Health Organization (WHO) classified the COVID-19 outbreak as a Public Health Emergency of International Concern on March 11, 2020. (PHEIC). The virus quickly spread throughout the world in the weeks that followed, causing governments in afflicted nations to enact lockdown measures to reduce transmission rates and avoid overcrowding in hospital emergency rooms. From 3 January 2020 to $4: 50 \mathrm{pm}$ CET on November 19, 2021, there were 554,459 confirmed cases of COVID-19 in Sri Lanka, with 14,072 deaths, according to WHO. This massive disaster hits the Sri Lankan economy badly and (Sri Lanka and the COVID - 19 crisis. Impact on the incomes of Sri Lankan households, 2020) stated, Because of the COVID issue, male-headed households are more likely to see a fall in household income than female-headed households. The (Gendered Impacts of COVID-19 on Employment in the Private sector, Sri Lanka, October 2020) indicate that COVID-19 had a negative financial impact on workers from all sectors, with over twothirds of respondents having at least one impact on their capacity to meet personal and family financial commitments in Sri Lanka. As a result, a large portion of the working people saw severe changes in their daily lives. People who commuted to work and had active social lives outside of their homes were forced to work from home (WFH), many employees were furloughed or laid off as various businesses and industries shut down, and emergency room staff, supermarket employees, and other essential employees were faced with a dramatic increase in workload and job strain. The objective of this study is to understand the impact of the pandemic on COVID-19 with a specific focus on the personal and official wellbeing of the PAC staff and recommend the possible measures to enhance their wellbeing from a social work perspective.

To examine this rapid study, the researcher, adopt 15 purposive samples from Northern, Eastern, and upcountry who are currently engaging as volunteers in PAC. The samples belong to different disciplines and different age groups and provided a good representation of the working population. The questionnaires with open and close-ended questions were distributed among the populations and excel was adopted to analyze the data. The results from this study will permit us to understand the staff's survival during COVID-19 especially in the area of personal and official wellbeing to Sri Lankan organizations. This paper explains in a sequence form of literature review which includes rich discussion about the theoretical aspects and encompasses with the relevant theories. After that, the researcher includes the methodological point of view of the research. Following that, the paper consists of a discussion of the collected and observed data with descriptions, explanations, and predictions to illuminate the findings. Finally, the researcher adds constructive conclusions with the social policy and social work practice implications.

\section{LITERATURE REVIEW}

COVID-19 is a global health emergency as well as a global economic threat. Employees and employers have faced a variety of unique obstacles as a result of the company and industry shutdowns that were established and mandated around the world to stop the virus from spreading. (Alexis 
Nicole Smith, 2019) indicates that, individual populations of shutdown-affected employees were overnight transformed into (a) "work from home" (WFH) workers, (b) "essential" or "life-sustaining" workers (e.g., emergency room medical personnel and supermarket employees), or (c) furloughed or laid-off employees seeking the nation's equivalent of unemployment benefits. Organizationally, the economic shutdowns and policy changes are expected to (a) fundamentally alter certain industries, (b) accelerate trends already underway in others, and (c) create possibilities for new industries to develop, as is common during wars and natural calamities. Given the ambiguity and scope of the COVID-19 shock, work and organizational psychologists must quickly use existing knowledge for the aim of sensemaking to assist individuals and organizations in managing risks while generating and implementing solutions. (Diamond, 1998) states, although a viable vaccine or treatment may be developed in time to restrict COVID-19's direct effects to less than a year, history is littered with examples of pathogenic bacteria wreaking long-term damage on communities and workplaces.

The influence of COVID-19 on the staff's personal and official well-being is the subject of this article. It provides opportunities to present a review of relevant literature as well as an evidence-based preview of changes that we expect in the wake of COVID-19 for both research and practice by focusing on topics that appeared most likely to be influenced by COVID-19 during the early stages of the pandemic. This review is divided into the following categories to arrange the discussion of the various ways in which the current epidemic is affecting the performance.

\section{Influence of the COVID-19 in Official life}

The COVID-19 not only threw typical work routines into disarray but also accelerated previously established trends concerning the shift of work to online or virtual settings. However, WFH was formerly more receptive to employee requests, whereas COVID-19 compelled many employees to work from home (MWFH).

During the early phases of the COVID-19 pandemic, roughly half of the organizations had more than $80 \%$ of their staff working from home, according to a study of 229 human resources (HR) departments, with considerable long-term increases in remote work expected following the pandemic (Gelfand, 2019) indicates, as a result of the requirement for millions of employees to WFH in response to COVID-19, recent remote work trends have intensified, aided by the advancement of connection and communication technology. While "remote work" is a wide term that includes "work from anyplace" (i.e., not necessarily from home), it is well recognized that some people, such as professionals who need to execute difficult tasks with limited peer interaction, prefer and are more productive when they WFH (T. D Allen, 2014). However, when a huge number of workers are obliged to work from home, many confront difficulties owing to basic concerns such as a lack of room in one's house to attend to work. Employees who live with others, for example, have more hurdles than those who live alone since they must manage other people's space as well. Apart from the difficulties that individuals may face when using WFH, it's worth noting that (a) many employers' reluctance to use WFH before COVID-19 stemmed from a perceived lack of control that employers would have over employees who were out of sight and reach and (b) there's reason to believe that new surveillance methods will be used in conjunction with various WFH arrangements. Employers were using and developing technology to track employees' locations even before COVID19 (D. P. Bhave, 127-164). Although managing by walking about is not possible when employees work remotely, virtual sightlines have become possible because of the fast-growing use of videoconferencing. However, these virtual sightlines carry a danger of increasing perceived stress and invading privacy. There is also evidence that such remote and automated monitoring can lead to decision-making centralization and (in the absence of countervailing action) reduced creativity among personnel at lower organizational levels (P. C. Nell, 2020).

The previous study has found that virtual teams lack the communicative richness of face-to-face teams (Luis L. Martins, 2004), and that classic teamwork issues like conflict and coordination may quickly increase (Mark Mortensen, 2001). Virtual teams should build structural scaffolding to reduce disputes, align teams, and ensure safe and comprehensive information processing. Prior research has proven the necessity to define team procedures, establish team goals, and incorporate structural solutions to encourage psychologically safe dialogues, particularly in virtual teams (Cristina B. Gibson, 2006). COVID-19's increased team virtuality may have an impact on assisting and pro-social behavior. While physical distance between coworkers may reduce helping behaviors in the short term, previous research has shown that people should be bolder in asking for help because people are more willing to help, and provide better quality help, than is commonly assumed, perhaps especially during times of crisis. The sense that asking for assistance might be uncomfortable, awkward, or embarrassing is a common obstacle, however "best practices" in virtual assisting can help help-seekers overcome these psychological barriers by protecting personal privacy and avoiding stigmatization as well as providing faith that things will improve if assistance is received (McDermott, 2017). On the other hand, previous research has shown that online teams are more effective at brainstorming than face-to-face teams (DeRosa, 2007). Remotely engaging colleagues, on the other hand, tend to overlook the creative advantages that might come from regular face-to-face encounters, according to research focusing on individual performance (Allen, 2015).

In the crucible of a crisis, the role of leaders in determining organizational outcomes that have a broad influence on personnel at all levels is extremely evident and crucial in basic 
ways. It's encouraging to know that leadership can function successfully from a distance, especially with the COVID-19 situation needing millions of employees from various hierarchical levels to WFH. In the crucible of a crisis, the role of leaders in determining organizational outcomes that have a broad influence on personnel at all levels is extremely evident and crucial in basic ways. It's encouraging to know that leadership can function successfully from a distance, especially with the COVID-19 situation needing millions of employees from various hierarchical levels to WFH. According to a previous study, great leaders are those who are competent in an area and can make the appropriate judgments while reassuring others with a balanced combination of optimism and reality about the future. In other words, good leaders attempt to portray vision as a symbolic condition of events with which they may work (at any moment) (Antonakis, 2016).

How evaluation and appraisal systems will work is one of the more particular leader-subordinate actions that will be necessary to examine regarding COVID-19. Without the ability to physically supervise subordinates as in an office context, there may be a shift to results-focused evaluation, which is generally beneficial in a previous study. Working remotely, on the other hand, may limit subordinates' opportunities to get feedback from leaders over longer periods, and past research has linked a lack of learning opportunities to weaker organizational commitment and a higher risk for turnover (C Vandenberghe, 2019).

\section{Influence of COVID-19 in personal and mental well-being}

Aside from the immediate impact of COVID-19, there are likely to be a variety of social-psychological, health-related, and economic costs for individuals, including those (a) whose work was made virtual or remote, (b) who continued as "essential" workers, and (c) who were laid off either temporarily or permanently as a result of the pandemic.

Workers are likely to be badly impacted by the loss of social connections - for those who were laid off and those who were obliged to WFH. High-quality social contacts, including informal discussions among employees, are important for mental and physical health in previous studies (Diener, 2009). Handshakes that are recognized to be beneficial for social interaction (Schroeder, 2019) have been banned. In light of this, both the mandate to WFH and attempts to find workplaces that allow physical distances are likely to have unintended consequences that affect people's mental and physical health.

Loneliness, a psychologically unpleasant sensation that emerges from people's subjective sense that their personal and social needs are not sufficiently satisfied, is more insidious than the loss of social ties, and it was previously regarded as "an epidemic" before this pandemic (Murthy, September 26, 2017). Employees' emotional commitment, affiliative behaviors, and performance have all been proven to be negatively impacted by workplace loneliness. While we found that virtual contacts are lacking in-depth, a more serious consequence of online communications is that misunderstandings in the absence of nonverbal cues are more likely to raise employees' fears of being rejected interpersonally, adding to loneliness (Allison L. Williams, 2018).

Given the pandemic's uncertainty, businesses must actively support their employees' health and well-being. Based on the work demands-resources hypothesis (Bakker, 2017), there is significant variation in how COVID-19 has influenced both the needs and resources of various positions across and within industries. Many workers' working circumstances appear to have deteriorated, according to evidence. COVID-19 has contributed to a higher chance of employees experiencing job burnout- $\mathrm{a}$ chronic stress condition characterized by persistent feelings of weariness and a detached attitude toward work-as a result of such pressures (Bakker A. B., 2017). Furthermore, constant exposure to COVID-19 media news encourages rumination repetitively and passively thinking on distress symptoms, as well as probable causes and implications of these symptoms.

Employees will require resources to appropriately deal with pandemic-specific and generically unclear employment demands. Organizations may utilize top-down (or support bottom-up) initiatives to care for employee health and wellbeing to restore the balance between job demands and resources to help address this. Organizations and their leaders might consider giving (a) immediate concrete resources, such as information (e.g., regarding working from home, transmission prevention), employee support programs, or counseling, therapy, and training as beginning point (b) psychological resources like as feedback, encouragement, and motivation from their staff via video conferences regularly. Beyond the systemic shocks of COVID-19, research that records and determines which types of such activities are most effective can offer advantages. Future studies should also look at whether structural efforts to improve working conditions through job redesign and job crafting are as effective now as they were before COVID-19 (Oprea, 2019).

Given previous research indicating that organizational and societal inequalities feed into one another, there are reasons to be concerned that increased inequality following COVID-19 will contribute to a downward spiral of negative workplace trends such as decreased work centrality, increased burnout, absenteeism, deviant behaviors, bullying, and turnover (Bapuji, 2020).

Furthermore, employment insecurity following COVID-19 is likely to inspire increased risk-taking and presentism among low-paid workers, thus increasing public health hazards of disease dissemination. Finally, if social and economic inequality rises as a result of COVID-19, civilizations may face social discontent and political instability (e.g., protests, riots). As a result, more organizational efforts to reduce 
inequality should help to prevent the negative spiraling that would otherwise occur.

\section{METHODOLOGY}

The participants were all volunteers in PAC, who belongs to multi-disciplinary work settings. The data were collected via a questionnaire that consists of both open-ended questions and closed-ended questions. With the help of excel, the data was analyzed. The researcher took purposive sampling with the purpose of researching within the organization itself, including Northern, Eastern, and Central Province. Because of the time limitation, the researcher adopts 15 samples overall to complete this rapid study.

Although this research was conducted after the third wave in Sri Lanka, it focused on the overall impact of the COVID-19. The main limitation of this study is the limited participants and the duration of data collection. Because of considering the situation, the researcher collected the data via phone and each respondent spend nearly 20 minutes answering the questions.

\section{DISCUSSION}

The data for this study was collected mixed questionnaire and analyzed via thematic and excel formats. The researcher was able to find out the COVID-19 impact on the Personal and Official well-being of PAC staff. Overall, 15 samples were selected from Northern, Eastern, and Central provinces. Out of the 15 participants, 6 were female and 9 were male. 4 people experienced COVID-19 virus infection.

The total number of respondents who answered all the questions of the survey is 15 volunteers. Of these, $40 \%$ of respondents were females and $60 \%$ of the respondent were males. The survey includes several questions about the personal and official wellbeing questions of volunteers, which directly and indirectly affect their well-being. The discussion part will be undertaken by main three phases. They are the knowledge about the COVID-19, the impact of personal life, and the impact on work-life wellbeing.

Phase I: The knowledge of COVID-19

\section{Chart 01}

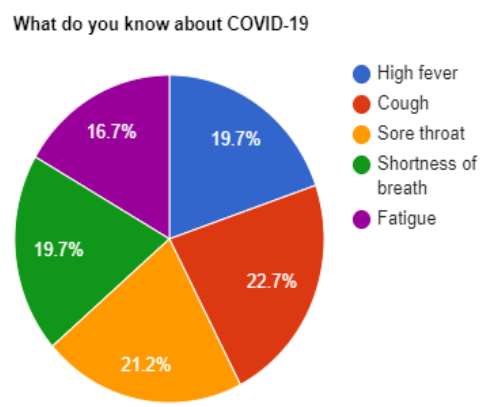

The data in Chart 01 shows, what do people know about COVID-19. It indicates that $19.7 \%$ of the whole respondents were aware of the high fever, $22.7 \%$ of respondents were aware of the cough, $21.2 \%$ of the respondents were aware of the sore throat, $19.7 \%$ of the respondents were aware of the Shortness of breath, and $16 \%$ of the respondents aware about the fatigue. Adding to this, respondents indicate that headaches and dizziness are the common symptoms of the COVID-19. Also, people state that COVID-19 is an infectious virus, it needs a high level of medical concerns and high cost, it usually affected elders and children comparting to adults and it is intentionally spread the virus by China.

Chart 2

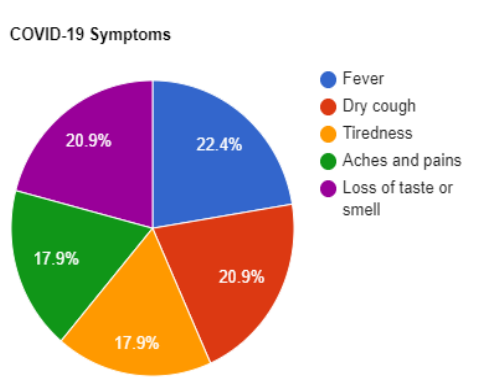

Chat 2 indicates the knowledge level of the respondents in understanding the COVID-19 symptoms. $22.4 \%$ of the respondents were aware of the fever, $20.9 \%$ of the respondents were aware of the dry cough, $17.9 \%$ of the respondents were aware of the tiredness, $17.9 \%$ of the respondents were aware of the aches and pains, and $20.9 \%$ of respondents aware about the loss of taste and smell. Other than these given symptoms, people are aware of the headache, breathing difficulties, skin rashes, chest pain, and confusion.

According to the (Symptoms of COVID-19, 2021) COVID-19 has been linked to a wide spectrum of symptoms, from minor aches and pains to serious sickness. Symptoms might emerge anywhere from 2 to 14 days after being exposed to the virus. Symptoms might range from moderate to severe. COVID-19 Fever, or chills may accompany these symptoms. Coughing, shortness of breath or trouble breathing, exhaustion, muscle or body pains, new loss of taste or smell, headache a scratchy throat, If have congestion or a runny nose, nausea, and vomiting, as well as diarrhea. When comparing the information provided by the respondents with the Symptoms of COVID-19 from the CDC, it reveals most of the respondents are aware of symptoms caused by COVID-19.

In the attempt of seeing the understanding of the COVID-19, 4 respondents out of 15 were directly experienced COVID-19 and from them, 2 were quarantined in quarantine center and the rest were quarantined in their own home. The victims of COVID-19 explained that they were severely struggling with body pain and high fever, and they couldn't be able to found the spreader of the virus. The rest of the respondents, 
understand the COVID-19 by stating, it's a virus and it came from China, it hits massive economic fall in the country and affects all people directly and indirectly. It also provides lots of new symptoms and a high range of pneumonia cause death. $60 \%$ of the respondents experienced at least one with COVID19 from their close circle. According to the World meter updates, Sri Lanka experienced 559,378 cases so far (November 24, 2021). From this comparison, all adults in Sri Lanka have heard the word 'Coronavirus' at least once in their lifetime.

(Xiaohui Chen, 2020) indicates that, unbelievable government initiatives have been seen across the world in reaction to the COVID-19 epidemic. While these intervention policies vary by country and location, they consistently attempt to lower population interaction rates and indeed lessen the virus transmission. In the attempt of checking the respondent regarding government interventions, all respondents state that they are aware of the preventative measures implemented by the government in reducing virus spreading such as, spreading awareness via media and social media (15 respondents), implementing curfews (10 respondents), implementing lockdown with restrictions (11 respondents), quarantine the COVID affected people (15 respondents), implement islandwide travel restrictions (13 respondents), Isolation (11 respondents), stop international and national level tourism (8 respondents) and Providing dry rations and money for the Samurdhi beneficiaries (2 respondents).

According to (Mahees, June 2021) research study shows that, During the interviews, several respondents stated that the government exploits the COVID 19 management procedure to achieve some concealed political goals. Citizens are subjected to quarantine restrictions as a form of political control. It was also found that the corona epidemic and its expanding patterns are frequently used to disarticulate politically delicate subjects in the country. The epidemic is often exploited as a political shield against other socioeconomic issues that arise in the country. During election seasons, it is also utilized as a major political manifesto. The political slogans of both the government and opposition parties are based on the losses and benefits of COVID management tactics. In the recent past, the epidemic became the political platform for practically all of Sri Lanka's hard and soft power connections. In examining these statements with this research, 7 respondents out of 15 were stated that they are not satisfied with the government interventions during a pandemic. 2 respondents were stated that they are satisfied and 6 respondents out of 15 stated that they some extend satisfied with the government intervention measures. The people who are to some extend satisfied and not satisfied are recommending increasing the lockdown days, spreading awareness via media, imposing punishable offenses for the rule-breakers, and empowering digitalized systems for good transactions as some methods to prevent COVID-19 spreading.

\section{Phase II: Impact on Personal life}

This part consists of the discussion on the impact of COVID19 in the respondent's personal life. In understanding the respondent's personal life being as a person, 5 respondents out of 15 are worrying and feeling disappointed with this situation. 3 respondents say that they are vulnerable to getting infections and transmitted diseases due to their poor health condition. The rest of the population states, that they feel responsible as a person in preventing the situation from going from worst. This condition shows that the respondents are more engaged to react when they feel responsive. According to (Ganti, 2019) The degree to which individuals follow the recommendations supplied by a country's health sector will determine the efficacy of these measures in reducing disease spread. Social responsibility is defined as the obligation of civil people (individuals or businesses) to contribute to the advancement of the society in which they live.

In an attempt to see the personal life impact factors as a family member, 2 respondents stated as a father, they feel very responsible in taking care of the economic state of the family. One respondent state that, as a mother, it is very hard to maintain children in the family when they don't go to school. Four respondents said that as a sibling they don't have worries about anything happening in the county. But they are worried about going outside when the restrictions are imposed. Two respondents stated that, as young girls, they have to do the household works with their mother. One-person state, that as a wife she experienced arguments and misunderstandings are increasing when she is with her husband for a long period. The upheaval of social identities, habits, and obligations is known as social role disruption. The COVID-19 pandemic, which presents a danger not just to health and security but also to the social roles that underpin people's everyday lives, is currently causing such havoc on a worldwide scale. According to (Hale T, 2021) Our social roles, on the other hand, alter as the circumstances around us change. The current coronavirus (COVID-19) pandemic is causing worldwide upheaval, and joint attempts to stop it have resulted in fundamental and unprecedented changes in societal institutions and roles. Global COVID-19 instances continued to climb in August 2021, and societal structures remained in turmoil and chaos, with approximately $60 \%$ of the world's population subject to some type of movement restriction.

In understanding the affected needs and services as personal life factors, people experienced barriers to purchasing basic food items during the lockdown. The people who infectious COVID-19 positive have struggled without others' help in fulfilling their basic needs. Also, two among them quarantined in the house and it affects their co-members also. Among the respondents, three have experienced the loss of a loved one during the pandemic. In their safety and security aspect, five out of 15 were lost their job and experienced a severe economic downfall. 6 were experienced a lack of income by their entrepreneurship livelihood. The people who experienced COVID-19 were faced emotional depression 
when they feel alone and stigmatized. One out of 15 was sold owed property to function the family. When looking at the psychological effects of the quarantine, it became clear how important it is for people to feel like they are a part of society, which is a component of psychological well-being that is frequently overlooked. Public health experts feel that social isolation is the best way to prevent the virus from spreading. Although it is impossible to forecast how long the epidemic would last, we are fully aware of the terrible impact these measures will have on society, relationships, and interactions, particularly the empathic process. When examining this element in the context of the current epidemic, an increase in opposed opinions and attitudes may be seen. On the one hand, people sympathize with those who are suffering (neighbors, friends, and family who are going through difficult times), advocating actions like "suspended expenditures." For instance, solidarity and humanitarian efforts, as well as food and medicine delivery to individuals who are unable to travel to the store. On the other side, a segment of society feels "forced empathy." This element may be pushed further by the use of technological equipment, which may lead to the depersonalization of relationships by imposing a sense of intimacy, at least virtually. The hyper connection of feelings becomes a means of reducing self-isolation and its repercussions, in contrast to Durkheim's (1858-1917) view of society as a distinct entity based on social facts (Durkheim, 1922).

\section{Phase III: Impact of Official life}

This part consists of the impact of COVID-19 on the official life of the respondents. In the attempt of identifying the working condition and the working opportunity during COVID-19, two respondents state that they are unable to go for daily work because of the lockdown. 7 respondents responded that they continue their works from home via virtual platforms. Out of these 7 respondents who are doing WFH, they feel happy when working at home than working in an office. Two respondents who are working in governmental organizations have engaged in their part-time business during the lockdown. The rest of the respondentstate that they are unemployed and still searching for a job. Workers must be flexible to adapt to changing market requirements in this competitive environment. Workers face several issues as a result of culture, technology, and changing work environments, among other factors. Because individuals are now working from home, firms are requiring higher levels of efficiency from them. Because people must balance their job and family duties, it is common for one of them to take precedence over the other, resulting in an imbalance between home life and work in the current working environment. (MS. PRITHIVI, 2020).

In understanding the decision-making opportunity during the pandemic, 4 respondents gain average level growth in their capacity and 2 responded felt bad in making decisions. The rest of the people took timely decisions in their working place and their family life too. In understanding their interaction with their co-members in the working place, five out of 15 were responded negatively because of their intensive workload load, poor health factors, and the absence of conducting field-related works. One out of 15 was positively responded because of the pre-planning and maintaining often communication with the line managers and colleagues. The rest of the working population responded that they somehow managed in maintaining neutral interactions. The respondents who are working in private and cooperate sectors (6 from the respondents) are facing pressure in their working hours. They indicated that they have to complete WFH reports, activity reports, and monthly weekly updates to their higher authorities. The respondents who are working in the government sector (2 respondents) leisurely spend their working hours with their family members. Three out of 15 respondents were stated that they are continuing their working hours as usual. The work-life balance refers to the creation and maintenance of supportive healthy work environments that allow workers to strike a balance between work and personal duties, hence increasing employee loyalty and productivity. According to a large Canadian survey, one out of every four employees had significant levels of conflict between work and family interference, as well as caregiver stress. When role overload is included, over $60 \%$ of employees questioned suffer work-family conflict. Managers and professionals frequently report greater levels of workfamily conflict as a result of their long work hours. Job security, supervisory support, colleague support, work expectations or overload, work role conflict, work role ambiguity, job unhappiness, and significant use of communication technology that blurs the lines between home and work are some of the other factors. Therefore, work-life have to be maintained to lead a healthy life.

\section{CONCLUSION}

It can be said that the personal and the official life are the most common part for an average adult. From the above discussion, the indicators which affect the official and the personal life have clearly been shown by the researcher. Adding to that, the factor of knowledge on COVID-19 was pointed out to prove that the respondents have enough understanding about COVID-19. The current research contributes to our knowledge of the COVID-19 crisis' influence on work and personal life. It demonstrates the correlates of greater negative/positive perceived consequences. Employees whose employment contracts were impacted by the crisis appear to have had the most detrimental effects on their work lives. This emphasizes the critical importance of under/ unemployment in a crisis, as employment is linked to several health-promoting elements that cannot be replaced in any other way (Jahoda, 1982). Furthermore, social isolation has had the greatest damaging impact on the private lives of employees who live alone. As a result, psychological first aid, which is also available online, should be created, with a focus on these vulnerable populations. Employers must ensure that workers with 
shortened contracts or working hours maintain tight social links and receive emotional assistance from the social work point of view. Furthermore, people who have lost half of all of their income require immediate financial assistance. Because of the COVID-19, employees had a more beneficial impact on their personal lives than newcomers, new WFH rules should include training and peer exchange on how to develop constructive routines that are compatible with their personal lives. Employees would be able to define their preferences ahead of time and tailor their work environment accordingly. Furthermore, a rise in leisure time was especially beneficial to personal life. More leisure time helps people to devote more time to things they enjoy, which can help with recovery and detachment from work, as well as mental health in general. As a result, employees may be taught how to make the most of their free time to amplify these positive benefits. To summarize, this research adds to recent evidence that the Covid-19 issue and related lockout measures have a mixed impact. Rather, it affects vulnerable groups of people who require specialized assistance, while the majority of the population remains healthy or even improves in their daily lives.

\section{REFERENCES}

[1] Alexis Nicole Smith, M. B. (2019). Making the invisible visible: Paradoxical effects of intersectional invisibility on the career experiences of executive Black women. Academy of Management Journal, 1705-1734.

[2] Allen, T. D. (2015). How effective is telecommuting? Assessing the status of our scientific findings. Psychological Science in the Public Interest, 40-68. doi:https://doi.org/10.1177/1529100615593273

[3] Allison L. Williams, A. C. (2018). Improving resilience among employees high in depression, anxiety, and workplace distress. International Journal of Research in Management, 4-22.

[4] Antonakis, J. B. (2016). Charisma: An ill-defined and ill-measured gift. Annual Review of Organizational Psychology and Organizational Behavior, 293-319. doi:https://doi.org/10.1146/annurev-orgpsych-041015-062305

[5] Bakker, A. B. (2017). Job demands-resources theory: Taking stock and looking forward. Journal of Occupational Health Psychology, 273-285. doi:https://doi.org/10.1037/ocp0000056

[6] Bakker, A. B. (2017). Job demands-resources theory: Taking stock and looking forward. Journal of Occupational Health Psychology, 273-285. doi:https://doi.org/10.1037/ocp0000056

[7] Bapuji, H. E. (2020). Organizations and societal economic inequality: A review and way forward. The Academy of Management Annals, doi:https://doi.org/10.5465/annals.2018.0029

[8] C Vandenberghe, G. L. (2019). A dynamic model of the effects of feedback-seeking behavior and organizational commitment on newcomer turnover. Journal of Management. doi:https://doi.org/10.1177/0149206319850621

[9] Cristina B. Gibson, J. L. (2006). Unpacking the Concept of Virtuality: The Effects of Geographic Dispersion, Electronic Dependence, Dynamic Structure, and National Diversity on Team Innovation. SAGE Journals. doi: https://doi.org/10.2189/asqu.51.3.451

[10] D. P. Bhave, L. H. (127-164). Privacy at work: A review and a research agenda for a contested terrain. Journal of Management, 2020.

[11] DeRosa, D. M. (2007). The medium matters: Mining the longpromised merit of group interaction in creative idea generation tasks in a meta-analysis of the electronic group brainstorming literature. Computers in Human Behavior, 1549-1581. doi:https://doi.org/10.1016/j.chb.2005.07.003

[12] Diamond, M. J. (1998). Guns, germs, and steel: A short history of everybody for the last 13,000 years. New York: Random House, New York.

[13] Diener, E. (2009). Time, money, and subjective well-being. Salt Lake City.

[14] Durkheim, E. (1922). Education et Sociologie. Milano: Ledizioni.

[15] Ganti, A. (2019). Social Responsibility. John Hopkins University and Mediciner Retrieved from https://www.investopedia.com/terms/s/socialresponsibility.asp

[16] Gelfand, M. (2019). Rule makers, rule breakers: Tight and loose cultures and the secret signals that direct our lives. New York: Scribner. ( October 2020). Gendered Impacts of COVID-19 on Employment in the Private sector, Sri Lanka . Colombo 2, Sri Lanka: IFC Women in Work Program.

[17] Hale T, A. N. (2021). A global panel database of pandemic policies. Oxford COVID-19 Government Response Tracker.

[18] Jahoda, M. (1982). Employment and unemployment: a socialpsychological analysis. Cambridge: Cambridge University Press.

[19] JanekMusek, M. P. (2014). Personal Well-Being. Encyclopedia of Quality of Life and Well-Being Research. doi:https://doi.org/10.1007/978-94-007-0753-5_2148

[20] Luis L. Martins, L. L. (2004). Virtual Teams: What Do We Know and Where Do We Go From Here? Sage Journals. doi:https://doi.org/10.1016/j.jm.2004.05.002

[21] Mahees, M. T. (June 2021). Politics of Corona Pandemic in Sri Lanka: A Sociological Analysis. Research Gate, 871-875.

[22] Mark Mortensen, P. J. (2001). CONFLICT AND SHARED IDENTITY IN GEOGRAPHICALLY DISTRIBUTED TEAMS. International Journal of Conflict Management, 1044-4068. doi:https://doi.org/10.1108/eb022856

[23] McDermott, R. C.-L. (2017). Hope for help-seeking: A positive psychology perspective of psychological help-seeking intentions. The Counseling Psychologist, 237-265. doi:https://doi.org/10.1177/0011000017693398

[24] MS. PRITHIVI, D. A. (2020). A STUDY ON IMPACT OF COVID IN WORK LIFE BALANCE OF EMPLOYEES IN CHENNAI. Journal of Ancient History and Archeology.

[25] Murthy, V. (September 26, 2017). Work and the Loneliness Epidemic :Reducing isolation at work is good for business. Harvard Business Review Home.

[26] Oprea, B. T. (2019). Effectiveness of job crafting interventions: A meta-analysis and utility analysis. European Journal of Work and Organizational Psychology, 723-741. doi:https://doi.org/10.1080/1359432X.2019.1646728

[27] P. C. Nell, N. F. (2020). Avoiding digitalization traps: Tools for top managers. In Business Horizons. Advance online publication.

[28] Schroeder, J. R. (2019). Handshaking promotes deal-making by signaling cooperative intent. Journal of Personality and Social Psychology, 743-768. doi:https://doi.org/10.1037/pspi0000157 (2020). Sri Lanka and the COVID - 19 crisis. Impact on the incomes of Sri Lankan households. UNICEF .

[29] Symptoms of COVID-19. (2021, February 22). Retrieved from Centers for Disease Control and Prevention : https://www.cdc.gov/coronavirus/2019-ncov/symptomstesting/symptoms.html

[30] T. D Allen, E. C. (2014). Work-family boundary dynamics. Annual Review of Organizational Psychology and Organizational Behavior.

[31] Xiaohui Chen, Z. Q. (2020, May 13). COVID-19: Government interventions and the economy. Retrieved from VOXeu: https://voxeu.org/article/government-interventions-covid-19-andeconomy 